\title{
Invenção e produção de encontros no território da diversidade: cartografia de um Centro de Convivência ${ }^{1}$
}

\author{
Juliana Maria Padovan Aleixo ${ }^{a}$, Elizabeth Maria Freire de Araújo Lima ${ }^{b}$ \\ ${ }^{a}$ Centro de Convivência Rosa dos Ventos, Serviço de Saúde Cândido Ferreira, Campinas, SP, Brasil.

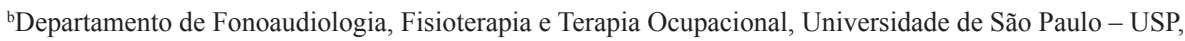 \\ São Paulo, SP, Brasil.
}

\begin{abstract}
Resumo: Introdução: Este artigo aborda parte da experiência de gestão de um Centro de Convivência (Cecos) em Campinas. Trata-se de um equipamento/dispositivo que compõe a rede psicossocial, orientado por diretrizes da Reforma Psiquiátrica, SUS e Atenção Psicossocial, dialogando com práticas nos campos das artes, da cultura e do lazer. Ainda, contextualizamos historicamente a origem dos Cecos em São Paulo e Campinas para poder chegar ao campo de nossa pesquisa, o Ceco Rosa dos Ventos. Objetivo: O Ceco é nosso campo, e sua produção, nosso principal objeto de interesse. Assim, entre os principais objetivos, destacamos a análise de suas produções híbridas em um território de múltiplos, no plano dos encontros. Dessa forma, ampliam-se, no campo das práticas em saúde mental, possibilidades diversas de clínica, trabalho e gestão. Método: Trabalhamos com a pesquisa-intervenção e com a cartografia, mapeando o plano dos encontros e suas produções sensíveis no cotidiano do Ceco, pondo-se à escuta das dissonâncias e rompendo com modelos hegemônicos de cuidado em saúde. Resultados: Entre os resultados cartografados neste artigo, mapeamos as produções híbridas dos Cecos, destacando o hibridismo entre a clínica, a arte e a cultura, assim como o hibridismo das produções clínicas e do cuidado em saúde. Conclusão: As produções do Ceco radicalizam as potências das tecnologias leves, seus movimentos, suas mutações, suas ancoragens no território do caos. Trata-se de experiências a serem compartilhadas e que se apresentam enquanto possíveis linhas de abertura ao sufocante momento de massificação em que se vive no contemporâneo.
\end{abstract}

Palavras-chave: Saúde Mental, Terapia Ocupacional, Subjetividade.

\section{Invention and production of encounters on diversity's territory: cartography of a Community Center}

\begin{abstract}
Introduction: This article discusses part of the management experience of a Community Center (Ceco) in Campinas; equipment/device that composes the psychosocial network, guided by Psychiatric Reform guidelines, SUS and Psychosocial Attention, dialoguing with practices in the fields of arts, culture and leisure. We historically contextualize the origin of the Cecos in São Paulo and Campinas, reaching the field of our research, Ceco Rosa dos Ventos. Objective: The Ceco is our field, and its production is our main object of interest. Therefore, among the main objectives, we highlight the analysis of its hybrid productions in a variable territory, in the level of the meetings. Thus, expanding in the field of mental health practices the diverse possibilities of clinic, work and management. Method: We work with intervention, research and cartography, mapping the plan of the meetings and their sensitive productions in the daily life of Ceco, listening to the dissonances, breaking with hegemonic models of health care. Results: Among the results mapped in this article, we map the hybrid productions of the CECOS, highlighting the hybridity between the clinic the art and the culture and the hybridity of the clinical productions and health care.
\end{abstract}

Autor para correspondência: Juliana Maria Padovan Aleixo, Centro de Convivência Rosa dos Ventos, Rua Abolição, 2965, Vila Joaquin Inácio, CEP 13045-750, Campinas, SP, Brasil, e-mail: aleixojuliana95@gmail.com

Recebido em Jul. 5, 2016; $1^{\text {a }}$ Revisão em Jan. 24, 2017; 2 ${ }^{\text {a }}$ Revisão em Abr. 29, 2017; Aceito em Maio 22, 2017 
Conclusion: Ceco's productions radicalize the powers of light technologies, their movements, their mutations, their anchorages in the territory of chaos. These are experiences to be shared and present themselves as possible lines of openness to the suffocating contemporary massification.

Keywords: Mental Health, Occupational Therapy, Subjectivity.

\section{Introdução}

Os Centros de Convivência (Cecos), ou Ceccos (Centros de Convivência e Cooperativas), são espaços pensados no decorrer do processo da Reforma Psiquiátrica e Atenção Psicossocial para circulação, inclusão, socialização e promoção de encontros entre os usuários da saúde mental e a população/comunidade geral.

As primeiras experiências no Brasil nasceram no município de São Paulo, no final na década de 1980. Eram serviços intersecretariais, afinados com o ideário da Reforma Psiquiátrica e, portanto, com a superação do modelo hospitalocêntrico (GALLETTI, 2004).

Os Cecos surgiram como dispositivo de uma rede articulada de atenção à saúde mental, porém com estratégias de açôes diferentes dos demais equipamentos de saúde, tendo como foco a produção de encontros e convivência por meio de oficinas, grupos e açóes comunitárias, alinhado com a ideia de promoção e prevenção da saúde.

Este serviço - o Centro de Convivência e Cooperativa (Cecco) - com características específicas quanto ao seu modo de funcionamento, tinha como principal instrumento de intervençấo com os usuários, o trabalho com as oficinas. Inspirado nos princípios da Reforma Psiquiátrica, esse equipamento tinha, em sua concepção, a proposta fundamental da Reabilitaçáo Psicossocial dos usuários da saúde mental, isto é, o trabalho das oficinas tinha, como finalidade, inserir os pacientes no circuito social (GALLETTI, 2004, p. 51).

O maior objetivo desse equipamento está na produção, mediaçáo e investimento em formas possíveis de encontros e convivência com a diversidade, buscando inclusão, cuidado, pertencimento, grupalidade e descoberta de outras possíveis formas de expressão da vida - inclusáo, aqui, pensada enquanto conexão, enquanto fabricação de redes sociais.

Problematizando essa concepçấo de inclusão, entendemos que os Cecos podem fazer mais do que "incluir pessoas excluídas". Os Cecos têm fabricado novos modos de sociabilidade, ou formas de sociabilidade alternativa, da qual todos nós estamos excluídos, na medida em que todos nós somos privados pelo projeto neoliberal de sociedade de viver um modo de convivência que valorize a ação coletiva (FERIGATO, 2013, p. 101).

Os Cecos trazem, em seu núcleo, a ruptura com o modo hegemônico de pensar a saúde apenas como remissáo de sintomas. Trata-se de um equipamento idealizado a partir das diretrizes do SUS e Atenção Psicossocial, com a promoção da convivência produtora de inclusão mediada pelo cuidado.

Para tanto, utiliza-se de espaços de produçáo, desenvolvendo oficinas de artes, esportes, artesanato, autocuidado, práticas integrativas, dança, teatro etc., e visando ao desenvolvimento de potencialidades, intersubjetividades, trocas, aprendizados, experimentação e construçáo de um campo diversificado na produção de encontros.

Esses parâmetros norteiam as açóes das equipes do Ceco e suas relaçóes com o território, com a rede de saúde, com a comunidade, fazendo interfaces com açôes culturais e artísticas, além de buscar construir a intersetorialidade ${ }^{2}$ na relação com diversos setores do território.

Para garantir o cuidado técnico e qualificado dessas açóes diante dessa ousada tarefa, os Ceccos em São Paulo foram se estruturando com equipes formadas por profissionais, como psicólogos, assistentes sociais, terapeutas ocupacionais, educadores, fonoaudiólogos, sociólogos e equipes de apoio (administrativo, higiene, vigia). Essa equipe, "inventora-facilitadora da convivência” (SÃO PAULO, 1992), buscava criar possibilidades múltiplas de comunicaçáo, oferecendo não mais uma "instituiçẫo total", mas um espaço institucional aberto, assim como um porto, de onde se podia partir e para onde se podia voltar (GALLETTI, 2004).

Atualmente, não se conta com a equipe proposta incialmente nos Ceccos em São Paulo. Além disso, há grande preocupação com a continuidade das experiências existentes, pois se trata de um dos poucos serviços próprios da prefeitura, mas com um número expressivo de profissionais em processo de aposentadoria.

Recentemente, os Cecos foram mencionados na política de saúde mental por meio da Portaria Ministerial no 3.088, de dezembro de 2011, na 
qual se oficializou a Rede de Atenção Psicossocial, encontrando-se no eixo da Atenção Básica e sendo definidos como:

Unidade pública articulada às Redes de Atenção à Saúde, em especial à Rede de Atenção Psicossocial, onde são oferecidos à população em geral espaços de sociabilidade, produção e intervenção na cultura e cidade. Os Centros de Convivência são estratégicos para a inclusão social das pessoas com transtornos mentais e pessoas que fazem uso de crack, álcool e outras drogas, por meio da construçáo de espaços de convívio e sustentaçáo das diferenças na comunidade e em variados espaços da cidade (BRASIL, 2011).

Porém, ainda não há uma regulamentação ministerial específica para os Cecos. Trata-se de uma situação que os fragiliza, pois coloca esses serviços à margem dos investimentos direcionados às políticas públicas. Há o reconhecimento de sua existência e sua expressão nas práticas de cuidado, mas não se conta ainda com o comprometimento para tornar os Cecos em serviços regulamentados com investimentos próprios, compondo o cenário com outros serviços da RAPS e fortalecendo as frentes alternativas ao modo asilar.

Atualmente, há uma grande mobilização dos Cecos em Campinas, São Paulo, Embu das Artes e Belo Horizonte, no sentido de agregar parcerias e construir diretrizes que possam embasar portarias, parcerias intersetoriais e maior envolvimento de atores políticos que viabilizem maior sustentação aos projetos.

\subsection{Centros de Convivência em Campinas}

Em Campinas, os Cecos não se estruturam a partir de uma regulamentaçáo do poder público e, com frequência, não contam com profissionais contratados especificamente para esses serviços ou funçôes. As experiências nasceram de diversas formas, no bojo dos movimentos da Reforma Psiquiátrica e do processo de cogestáo, iniciado em 1990, entre o Serviço de Saúde Dr. Cândido Ferreira e a Prefeitura Municipal de Campinas. Na medida do possível, foram assimilados os princípios e as características do modelo dos Ceccos de Sáo Paulo, no tocante à definição de espaço, população-alvo, atividades e objetivos.

São serviços na maioria das vezes, não planejados burocraticamente, não vinculados diretamente às açôes da gestão central, mas fruto de movimentos sociais de trabalhadores, usuários, de iniciativas de cooperação entre instituiçóes e comunidades, movimentos instituintes que se consolidam numa forma-Centro de Convivência que escapa às exigências e burocracias sanitárias, arcando com os ônus positivos e negativos desta característica (FERIGATO, 2013, p. 120).

Os projetos se instituíram a partir de 1997 com a prática de alguns profissionais da saúde de Caps e Centros de Saúde, aliados a experiências de coletividades em comunidades diversas, em parcerias com ONGs, núcleos assistenciais, casas de cultura, projetos ligados à educação, como a Fundaçáo Municipal de Ensino Comunitário (Fumec) etc.

Os frequentadores que acessam os Cecos em Campinas chegam por meio de distintas redes. São pessoas da comunidade local que "descobrem" o serviço de forma espontânea ou chegam por indicação de outros frequentadores. Há também os encaminhamentos construídos com os Caps, Centros de Saúde, Serviços Residenciais Terapêuticos, Núcleos assistenciais, Escolas e distintos equipamentos do território, além de frequentadores que chegam também de bairros distantes e até de cidades próximas. São características que compóem o cenário da diversidade do Ceco. São crianças, adolescentes, idosos, pessoas em situação de rua, população LGBTT, pessoas que trazem múltiplas circunstâncias ao espaço da convivência intergeracional, pulverizando os espaços de experiência e troca.

Os espaços físicos também refletem em uma grande diversidade. Há Cecos em espaços públicos, como praças, antigos centros comunitários e ONGs, e em casas alugadas, onde se faz necessário um grande trabalho para tornar público o espaço físico. Hoje, Campinas conta com sete Cecos, distribuídos em quatro distritos de saúde do município.

Sobre a diversidade de instauração e constituição dos Cecos,

Valorizamos esse movimento diverso da constituiçáo dos Cecos em Campinas, pois ele expressa por um lado, o caráter transdisciplinar desse dispositivo e por outro sua resistência em ser capturado por movimentos instituídos da Atenção Básica ou da Reforma Psiquiátrica, como acontece em muitos municípios com serviços como os Caps ou Centros de saúde [...]. Os Cecos anunciam a partir da diversidade de suas possibilidades de nascimento, sua multiplicidade de conexóes a diferentes institucionalidades, a diversos movimentos sociais e políticos, não estando capturado previamente como um dispositivo exclusivo 
da Reforma Psiquiátrica ou de qualquer outro campo (FERIGATO, 2013, p. 109).

A história de cada Ceco traz aspectos que imprimem marcas na constituição de cada espaço, transformando cada um desses Centros em uma proposta singular. $\mathrm{O}$ modo como se produzem os encontros, como se pensa a convivência, o modelo de saúde, o envolvimento da comunidade em cada Ceco, tem registros próprios que não estâo desvinculados de suas trajetórias. Ainda assim, muitos aspectos se produzem em rede, em consonância, em comum (FERIGATO, 2013).

\subsection{Centro de Convivência Rosa dos Ventos}

Partindo do contexto descrito anteriormente, ou seja, da rede de Centros de Convivência de Campinas, elegemos um desses dispositivos como campo de investigaçáo, o Ceco Rosa dos Ventos.

Inaugurado em 2005, o Ceco Rosa dos Ventos nasceu do Caps III da região sul de Campinas, em parceria com a Fumec. Parte da equipe do Caps idealizou um espaço para além do serviço de circulação e socialização dos usuários com a comunidade local. Iniciaram-se, entâo, as negociaçôes para o aluguel de uma casa próxima.

Com a forte parceria da educação, inicialmente o espaço passou a ser chamado de Casa-escola Rosa dos Ventos. As açóes começaram com as salas de aula para alfabetizaçáo de adultos e algumas oficinas de artesanato oferecidas por trabalhadores do Caps. Não havia uma equipe própria destinada ao serviço, assim estruturaram-se horas de trabalho de alguns funcionários do Caps.

O Fórum de Cecos de Campinas ${ }^{3}$ passou a fortalecer a política dos Centros, estruturando propostas de gestão e equipes próprias. O debate foi ampliado em torno desse tema nos fóruns de saúde mental com trabalhadores e gestores. Nesse momento, a Casa-escola Rosa dos Ventos passou a ser Centro de Convivência Rosa dos Ventos, pois suas açóes aproximavam-se das propostas dos Cecos.

Das atividades propostas, destacamos aquelas que acontecem na sede do Ceco, coordenadas pela equipe; as dos grupos em parceria com outros serviços da rede, que ocorrem no Ceco; e as dos grupos itinerantes, que acontecem fora da sede.

Muitas trajetórias dizem dessas possibilidades, muitas identidades, outros lugares a serem experimentados a partir do plano dos encontros.

Muitas Marias, Pedros, Paulos, Teresas, Anas...
Sáo esses encontros e suas produçóes que abordaremos neste artigo.

\subsection{O Ceco no plano das produções- fazeres em experimentação}

Nesse trajeto da experiência de gestão do Centro de Convivência, vemo-nos às voltas com o tema da produção-produtividade-indicadores, o qual inquieta, desassossega e desafia. Nos espaços de gestão, ao discutirem-se os serviços de saúde, financiamentos e investimentos, rapidamente aponta-se para os indicadores de produtividades. São produçóes de saúde, que expressam materialidade em seus indicadores quantitativos, sendo determinantes na validação e efetividade de um serviço. Um serviço com altos indicadores é um serviço produtivo que pode ser mais investido de financiamentos e de práticas que fortaleçam suas ações. Essa é a prerrogativa dominante nas discussóes capturadas pelas modulaçôes do capitalismo na área da saúde.

Assim, chegamos a um grande desafio. Como quantificar numericamente práticas que se estabelecem a partir dos encontros abertos, devires em experimentação, clínica em movimento, em que as ações instituintes inauguram o vir a ser de um serviço-dispositivo que se localiza estrategicamente à margem, na fronteira? No entretecer das redes, agenciando práticas de saúde, arte, cultura, lazer, borrando as margens formais de relação dadas, criando-se, nessa hibridização de múltiplos, processos que não se acomodam mais nas padronizações formais das açôes tradicionais nos campos descritos.

Como medir quantitativamente uma produção que não se adequa às categorias tradicionais? Como criar indicadores outros que se aproximem dessas práticas? Quais estratégias de visibilidade dar para essa produção que não se calcula na soma cartesiana, que não se enquadra nas portarias ministeriais, nas planilhas de produtividade, que não se apresenta a favor de lucros capitais?

Afinal, de quais produçôes queremos falar?

E, assim, retomamos a pergunta central que desencadeou nossa pesquisa: qual é a produção, no plano dos encontros, do Centro de Convivência Rosa dos Ventos?

Ao construir essa pergunta para pesquisa, pensamos o tema da produção da forma mais ampliada possível e, ao mesmo tempo, as singularidades do Ceco em questão. Produção no campo do trabalho, no campo das subjetividades, no campo da clínica, no campo das materialidades possíveis da produção: números, indicadores, financiamentos... E também 
a materialidade produzida pelos grupos e atividades desenvolvidas no Ceco, artesanato, pinturas, telas, esculturas de argila... Há também produções que adquirem materialidade e se transformam, como os bolos, pães, receitas produzidas em nossa movimentada cozinha... E como pensar a produçáo de grupos que acontecem com a música e a dança? Qual materialidade dessa produção que passa pelo agenciamento dos corpos, que dançam, que desterritorializam e se reterritorializam nos ritmos, sons, melodias, cantos, gestos?

Pergunta essa que nasce da tensão de se ocupar um lugar de gestáo, onde se responde por um Ceco e por uma produção que não dá conta de quantificar e mensurar as intensividades dos encontros produzidos. Pergunta que se torce na medida em que se esforça para se encontrar com tantas respostas possíveis.

Não se trata, então, de responder do lugar tradicional da gestão, qual a produção do Ceco em suas extensividades, em suas quantidades e partes de existência, mas sim cartografar do lugar de incômodo, do lugar de afetaçôes, do indizível, do incabível, dos interesses que nos capturam ao procurar por uma linguagem possível, construir o que acontece ali. $\mathrm{O}$ que acontece nessas linhas sensíveis, intensivas, menores, dissonantes, quase-mistérios que produzem mutaçôes vivas de vida em sua intensa expansão?

Movemo-nos, então, nas dissonantes produções que se harmonizam em uma ética do cuidado polifônica do Ceco, onde construímos nossa pergunta e nossos misteriosos interesses.

Interessamo-nos, assim, em cartografar produçôes que não cabem nas planilhas entregues mês a mês à Secretaria de Saúde. Interessamo-nos nas produçôes que escapam às prestações de contas, às avaliações reducionistas dos serviços, aos espaços áridos de discussão da gestão, que escapam ao viés da atenção gerenciada e dos gerencialismos predominantes.

Interessamo-nos por essas produções menores que não interessam à política macro de saúde, que não é absorvida nos planos gerencialistas, que náo é captada pelos olhares condicionados ao campo tradicional da produção de saúde, que não se apresenta nos serviços-chave da Reforma Psiquiátrica, no foco das produçóes maiores que mobilizam respostas centrais e normativas.

Ao nomearmos produçóes menores, aproximamo-nos da literatura menor, a qual, para Deleuze e Guattari (2014, p. 39), não é a de uma língua menor, em sentidos desqualificantes ou banalizáveis, mas, antes, a que uma minoria faz em uma língua maior. "Kafka diz precisamente que uma literatura menor é muito mais apta a trabalhar a matéria", caracterizada por um forte coeficiente de desterritorializaçáo da língua, ligação do individual no imediato-político, com intensos processos de agenciamentos coletivos.

Não há tẫo grande, nem revolucionário quanto o menor [...] fazer um uso menor de sua própria língua, supondo que ela seja única, que ela seja uma língua maior ou o tenha sido. Ser em sua própria língua como um estrangeiro [...] fazer desta um uso menor ou intensivo, opor o caráter oprimido dessa língua a seu caráter opressivo, achar os pontos de não cultura e de subdesenvolvimento, as zonas de terceiro mundo linguísticas por onde uma língua escapa, um animal se enxerta, um agenciamento se instala [...]. Sonhar o contrário: saber criar um devir-menor (DELEUZE; GUATTARI, 2014, p. 52-53).

Produçôes menores no campo do trabalho, no campo das subjetividades, no campo da clínica. Menores em usos intensivos em que se faz escoar, seguindo de linhas criadoras de fuga, em formas surpreendentes de desterritorialização, mutação, engendramentos.

Ao ocuparmo-nos das produçôes menores de um Ceco, interessamo-nos, particularmente, por esses tensores, escapes, graus de afecçôes que nos tocam nas forças sensíveis dos encontros, dos agenciamentos.

Também nos interessa a materialidade produzida nesses encontros. Pelos grupos e atividades desenvolvidas no Ceco: artesanatos, pinturas, telas, esculturas de argila... Há, também, produções que adquirem materialidade e se transformam, como os bolos, pães, receitas produzidas em nossa movimentada cozinha... E como pensar a produção de grupos que acontecem com a música e a dança? Qual materialidade dessa produção que passa pelo agenciamento dos corpos, que dançam, que desterritorializam e se reterritorializam nos ritmos, sons, melodias, cantos e gestos?

Sujeito, produção e consumo mostram-se como movimentos de um ato, movimentos de um processo, em que a produção se apresenta enquanto ponto de partida, enquanto movimento predominante, enquanto processo ininterrupto. É possível falar de produçáo como um plano, plano de constituição, de engendramento, fazendo-se permanente.

Barros e Passos (2012) pontuam que, ao revelarmos a dimensão da produção no campo, desnaturalizamos suas realidades e suas dicotomias constitutivas. O plano revelado apresenta-se enquanto processo de produção.

Seja o plano da constituição das práticas psi, o plano de criação do esquizofrênico, o plano 
de emergência do político, o plano é sempre uma processualidade, isto é, um se fazendo.

No plano da micropolítica, no cotidiano das relaçôes,

O termo produzir vincula-se a redes, conexōes, movimentos associados a formas de pensar, concepçóes de mundo e modos de agir em função das forças em disputa. A vida, enquanto campo de forças pode ser referida como uma sucessão de acontecimentos- de produções cujos efeitos, por sua vez, corporificam-se ampliando o produzir para as mais diversas formas de relaçôes, afetos, desejos, ideias, expectativas, subjetividades [...] (SCHEINVAR, 2012, p. 195).

Aqui o sujeito será efeito de um processo de produção, processo de subjetivação, plano de subjetivação ou criação de si. Produção do sujeito, produção inconclusa, heterogenética, nunca havendo esgotamento total da energia potencial de criação das formas. Produçóes plurais, polifônicas, híbridas, conectadas à experimentação das composições produção-processo-produto, movimentando-as, desestabilizando-as, permitindo o aparecimento do plano de forças de produção a partir do qual tal realidade se constitui.

Produzir é o encadeamento de práticas corporificadas material ou afetivamente. Produzir é afetar: propiciar um sentimento, criar um objeto, construir um desejo, fazer um movimento, construir campos de possibilidades. Os modos de ser, os desejos, as sensaçôes, as expectativas entendidas como subjetividades historicamente constituídas são produçóes, muitas vezes perceptíveis em sua singularidade. Entender as práticas é rastrear a historicidade na qual foram produzidas (SCHEINVAR, 2012, p. 196).

Colocar em análise o plano de produção dos encontros do Centro de Convivência, cartografar processos de produção em constante movimentaçáo, analisar as forças em cena... forças agenciadas a partir da produção dos encontros.

\section{Método}

É importante destacar que já habitávamos o território da pesquisa, também hibridamente, enquanto gestora do serviço, mestranda e coordenadora do grupo de dança do Ceco. As ferramentas de análise de implicação e sobreimplicação foram fundamentais para problematizar o lugar do pesquisador-cartógrafo nesse espaço, colocando em análise as potências e capturas de habitar esses lugares ao mesmo tempo. Diários de campo, registros fotográficos e vídeos também compuseram o material da pesquisa com suas devidas autorizações (usuários e equipe). Como o objeto de nossa pesquisa foi formulado a partir das produções híbridas do Ceco, foi necessária a aprovação do comitê de ética da instituição para acesso aos registros e arquivos dos grupos do Ceco, assim como submissão e aprovação à Plataforma Brasil (Protocolo CAAE 44453715.4.0000.5401).

Pensamos a pesquisa enquanto pesquisa-intervenção. Como toda pesquisa é intervenção, e toda intervenção em saúde é sempre uma atitude clínica-política, o campo de análise não se separa do campo da intervenção. Assim, compomos com um modo de pesquisa que visa acompanhar processos em constantes mutaçóes. Processos de subjetivaçóes, linhas de forças, colocando em análise forças de captura e de potência. Exercício ativo de um constante coengendramento entre produção de conhecimento, política e clínica, podendo ser a pesquisa uma via de produção de cuidado que possibilita a operação de mudanças (BARROS; PASSOS, 2012).

Ao pensar o Centro de Convivência enquanto campo de pesquisa-intervenção e suas produçóes no plano dos encontros, faz sentido a procura por referências nas quais o ponto de apoio é a experiência entendida como um fazer-saber, isto é, um saber que vem e que emerge do fazer (BARROS; PASSOS, 2012). Trata-se de pesquisar um serviço-dispositivo móvel em suas ações e produções, mapear uma extensa rede de conexôes e conversaçôes que o compóe, extrair da experiência de seus fazeres, seus saberes... Cartografar, mapear.

Cartografar acontecimentos e paisagens psicossociais no Centro de Convivência nos faz buscar a construção da pesquisa em ato, incluindo subjetividades em transformação que acompanhem o caminhar de um serviço híbrido, no qual se coloca em convivência a possibilidade da diferença na diferença, experienciando esse trabalho enquanto uma rede intensa de conversaçóes.

Diferentemente dos mapas, nos quais vemos a representação de um todo estático, a cartografia é um desenho que acompanha e se faz ao mesmo tempo que os movimentos de transformação da paisagem. "Paisagens psicossociais também são cartografáveis" (ROLNIK, 2011, p. 23). Acompanha e se faz ao mesmo tempo que o desmanchamento de certos mundos, sua perda de sentido e a formação de outros: "Mundos que se criam para expressar afetos contemporâneos, em relação aos quais os universos vigentes tornam-se obsoletos" (ROLNIK, 2011, p. 23). 
Para Suely Rolnik (2011), a tarefa do cartógrafo é dar língua aos afetos que pedem passagem. Para isso, espera-se que esteja mergulhado nas intensidades de seu tempo, atento às linguagens que encontra, devorando as que lhe parecem elementos possíveis para a composição das cartografias que se fazem necessárias. "O cartógrafo é, antes de tudo, um antropófago" (ROLNIK, 2011, p. 23).

Para o cartógrafo, tal como proposto por Rolnik (2011), as referências teóricas são produzidas com formas de pensar que podem vir de múltiplas cartografias conceituais. Teoria é sempre cartografia e se faz com as paisagens cuja formação ela acompanha. Assim, o cartógrafo absorve matérias de qualquer procedência, sem exclusão de linguagens ou estilos. "Todas as entradas são boas, desde que as saídas sejam múltiplas" (ROLNIK, 2011, p. 32). Por isso, o cartógrafo serve-se das mais variadas fontes, incluindo não só escritas e não só teóricas. Seus operadores conceituais podem surgir tanto de um filme quanto de uma conversa ou de um tratado de filosofia. Ele está sempre buscando elementos/alimentos para compor suas cartografias.

Verifica-se, assim, o critério de suas escolhas, descobrir que matérias de expressão, misturadas a quais outras, que composiçóes de linguagem favorecem a passagem das intensidades que percorrem seu corpo no encontro com os corpos que pretende entender.

Entender, aqui, não significa explicar e muito menos revelar. Entender no sentido de mergulhar na geografia dos afetos e, ao mesmo tempo, inventar pontes para fazer sua travessia, pontes de linguagem, de criação de mundos, enquanto veículo que promove a transição para novos mundos, novas formas de história (ROLNIK, 2011).

O cartógrafo busca criar os procedimentos em funçáo daquilo que pede o contexto em que se encontra, por isso náo segue protocolos normalizados, predefinidos.

A pesquisa faz-se assim como cartografia do meio em que o pesquisador está mergulhado na produção de mapas referentes aos encontros vividos nesses trajetos e aos afetos e sensações ali produzidas (LIBERMAN; LIMA, 2015, p. 183).

Suely Rolnik, em Cartografia Sentimental, descreve o manual do cartógrafo, isto é, o que o cartógrafo levaria no bolso: "Um critério, um princípio, uma regra e um breve roteiro de preocupaçôes (que se define constantemente)" (ROLNIK, 2011, p. 67).

O critério de avaliação é o grau de abertura para a vida que cada um se permite a cada momento.
O princípio é o extramoral; a expansão da vida é seu parâmetro básico e exclusivo, o quanto a vida está encontrando canais de efetuação.

A regra é agir e inventar estratégias tendo a vida como critério e sua defesa. E, nesse sentido, a regra é também uma regra de prudência que permite discriminar os graus de perigo e de potência, funcionando como alerta nos momentos necessários. Há um limite de tolerância para desorientação e reorientação dos afetos, um "limiar de desterritorialização". Sustentar a vida em seu movimento de expansão, eis a ética do cartógrafo (ROLNIK, 2011).

No Centro de Convivência, as práticas mostram-se conectadas às novas formas de produção e de sensibilidades no campo do cuidado na Atenção Psicossocial. Novas formas de fazeres, de cuidado, de trabalho, alargando, inovando e redimensionando o entendimento de cuidado e trabalho nesse campo de açôes, tornando necessária a composição de novas linguagens, novas referências, que possam trazer à cena novos regimes de visibilidade às práticas ali produzidas.

Pensar o Centro de Convivência enquanto campo de pesquisa póe em suspenso as fronteiras dos saberes, borrando margens, trazendo à cena composições inéditas, misturas, confusões, desestabilizaçôes... um campo que por excelência desterritorializa os campos formais de saberes e de lugares profissionais.

Assim, a cartografia, com seus critérios, princípios, regras e sua ética, mostra-se intrinsicamente conectada à produçáo do Centro de Convivência, trazendo aproximaçóes e elementos que permitem colocar em análise esse espaço enquanto campo da pesquisa-intervenção, colocar em análise suas potências, suas capturas, suas linhas de força, trazendo à cena a criação de novos regimes de visibilidade.

\section{Resultados: Cartografia dos Encontros no Ceco Rosa dos Ventos}

\subsection{Encontros com arte, cultura e clínica: produções híbridas}

No cotidiano das práticas do Centro de Convivência, construídas na interface com o universo da arte, cultura, práticas integrativas, práticas de lazer, deparamo-nos, frequentemente, com experimentaçóes estéticas que se expandem do campo da saúde, arte e cultura tradicionais.

São práticas que atravessam a fronteira que delimita esses campos e se conectam, agenciando-se hibridamente em um novo campo de difícil nomeação, 
no qual a arte se encontra com essas pessoas-margem que acessam o território do Centro de Convivência. Momentos estéticos em que subjetividades em obra possam construir-se a si mesmas, configurando e dando forma ao caos e às rupturas de sentido que, muitas vezes, habitam-nas (LIMA, 2006, p. 326).

Este fato tem um poderoso efeito sobre a vida das pessoas que experimentam estados clínicos... Cada sujeito ao construir um objeto, pintar uma tela, cantar uma música, faz algo mais que expor a si mesmo e o próprio sofrimento. Ele realiza um fato de cultura... $\mathrm{O}$ valor que determinadas produçôes podem ganhar, passando a interessar justamente por seu caráter de singularidade, dissidência, deriva e inacabamento, e sua circulação num coletivo, provoca um enriquecimento dessas vidas; e aqui estamos tomando a vida, e não a arte como critério. Ao se articularem aos modos de expressão dominantes, modos de expressão dissidentes atravessaram a linha divisória que os separavam da produção cultural, ganhando cidadania cultural... e um certo poder nas reais relaçóes de forças [...].

Trata-se de experiências-limite rejeitadas em alguma medida pelos campos instituídos da arte, da cultura, da saúde. Experiências de criação que se fazem sobre uma linha fronteiriça. Fragmentos estéticos ou performances que não podem ser reproduzidos e constituem momentos privilegiados em que arte, saúde, loucura e precariedade se conectam, colocando em xeque os limites entre arte e náo arte, entre arte e vida, arte e clínica (LIMA, 2006).

Assim, notamos um território intenso de produçôes híbridas do Centro de Convivência. Um constante caminhar entre uma regiáo fronteiriça na qual arte, cultura e clínica estão implicadas em suas conexôes, em suas dissonâncias, gerando um espaço de tensôes que provoca desestabilização entre os campos.

Vemos como desafio não reduzir essas produçóes a nenhum dos campos tradicionais, procurando encaixá-los, dando lugares mais facilmente legitimados e reconhecidos, mas manter aberta a tensão que essas produçôes instauram entre elas. Vivenciar o incerto, o inacabado, o transitório, o efêmero, que comporte as desterritorializaçôes e os desequilíbrios dos sujeitos dos quais se conecta.

O sentido aqui é o de encontrar ferramentas para recomposição, para reterritorialização de universos existenciais e para uma produção mutante de enunciaçấo.

\subsection{Encontros com a dança: produções clínicas e terapia ocupacional}

Nesse encontro, apresentamos uma cena vivida no grupo de dança do Ceco, espaço em que habitamos enquanto terapeuta ocupacional-coordenadorapesquisadora há cinco anos.

Cartografar as produções do Ceco nos coloca em meio a desafios diante de tantas experiências na diversidade. Multiplicidades de subjetividades em expressão na presença de muitas possibilidades artísticas, expressivas e clínicas. Em nossa pesquisa de mestrado, muitas cenas narradas e vivenciadas estão presentes, porém, para este relato, escolhemos o grupo de dança por se tratar de um espaço de trabalho corporal-clínico-artístico, no qual se expressa, pelos corpos, o indizível das palavras, dos gestos, colocando em cena outras formas de dar passagens ao vivido, apresentando o corpo como lugar de experimentação, de relação e produção de subjetividade. Também é nesse espaço que podemos pensar possibilidades da terapia ocupacional em um espaço como o Ceco.

Estar em um dispositivo no qual potencialmente as atividades artísticas, expressivas e corporais se apresentam como possibilidades de cuidado, convivência e troca nos conecta com o universo da terapia ocupacional. O foco das ações em terapia ocupacional pode acontecer no encontro em ato que se dá por meio de uma ação ou uma atividade. As linguagens da ação no plano coletivo são um dos muitos modos de conhecer a si mesmo, conhecer os outros, a cultura que vivemos, transformando e ressignificando projetos de vida.

Assim, a terapia ocupacional, dentro das abordagens artísticas e expressivas, amplia a construção de outras formas de expressão, compondo processos de criação na relação com esses recursos, ampliando repertório de habilidades e de experiências, agenciando transformaçóes subjetivas e construçáo de novos lugares sociais.

As atividades expressivas, como é o caso da dança, dos trabalhos corporais, da música e do teatro, têm sido cada vez mais utilizadas em terapia ocupacional, seja no uso direto dos métodos compondo ou não com outros recursos (argila, pintura, etc), seja para a compreensão do sujeito a partir de um olhar que privilegia o corpo e suas potencialidades [...] diferentes vivências nos campos das artes podem contribuir para que o sujeito se perceba como tal, identifique seus diferentes "modos de funcionamento" para em seguida, 
repensá-los e (re)construí-los. O corpo constitui, assim, um indicador fundamental para o conhecimento das histórias do sujeito, seus modos de funcionar, sua vida cotidiana, suas dores, tensóes, anseios, etc. (LIBERMAN, 2002, p. 40).

\section{Em Cena..}

Em uma chuvosa tarde de quinta, Maria chega timidamente ao grupo de dança do ventre que já havia iniciado. Começamos aquecendo em roda, alongando, apresentando-nos, ocupando pouco a pouco a pequena sala do Ceco. Convido-a para entrar na roda, apresento-me. O sorriso envergonhado, o corpo desajeitado, o olhar firme, curioso, procurando outros olhares, outros corpos, ajeitando-se ao lado de outras mulheres, outras Marias presentes no grupo. Há muitas Marias nessa Maria.

Seguimos nos preparando para dança, movimentando os quadris, explorando direçóes e formas, nas batidas laterais, nos acentos verticais, nos tremidos, deslocando, girando, caminhando, experimentando e descobrindo as possibilidades de movimentos dessa complexa estrutura feminina ao som dos ritmos e instrumentos percussivos árabes. Maria sorri e mostra ginga, atenta aos corpos que a rodeiam. Corpos que se soltam, que se encontram, que se conversam, que se esbarram e se afastam brincando, que se agenciam em movimento. $\mathrm{O}$ sentimento de alegria se expande pela sala.

Vamos aos movimentos ondulatórios, sinuosos redondos, oitos, ondulaçóes de ventre, encontrando direçóes e deslocamentos diversos em cada possibilidade. Leveza, delicadeza, introspecção, concentração, sensualidade, feminilidade. Maria se desajeita, enrijece-se, olha para os lados, percebe o grupo mais atento e não desiste. Segue no desafio de experimentar seu corpo de mulher nos passos que convocam o feminino a pulsar.

Caminho pelo grupo procurando por processos a serem mediados e facilitados. Percebo Maria tensa. Toco em seu quadril, e juntas desenhamos os oitos com nossos corpos. Ao soltar as mãos, tranquilamente seu quadril segue dançando, explorando as direçóes propostas. É imediato o brilho que toma conta de seus olhos, o sorriso largo volta a aparecer no rosto sofrido.

Maria está com os filhos em um abrigo para mulheres vítimas de violência doméstica. Já passou em tratamento pelo Caps e Centro de saúde. Em seu acolhimento, feito antes de entrar no grupo, relatou não poder dar seu endereço. Regra dos abrigos que hospedam mulheres que passaram com seus filhos por inúmeras situaçóes de violência com seus parceiros.
Voltando ao grupo, antes de finalizar nosso encontro, proponho um momento de improviso. Ouvir a música, experimentando os movimentos explorados, deixando o corpo conduzir para as direçóes que sentir, que desejar. Conectar-se, arriscar-se. Maria não hesita. Fecha os olhos e dança. Sorri, gira, solta os braços, ora desengonçada e enrijecida, ora precisa com seu largo quadril marcando os ritmos árabes, com ginga e discreta feminilidade que já acena em cena.

Ao final, apresentamo-nos novamente para que Maria conheça as outras frequentadoras. Ao se apresentar, diz:

Meu nome é Maria. Soube daqui pelo SOS Mulher. Estou desempregada e preciso fazer alguma coisa. Alguma coisa por mim. Alguma coisa que me afaste de tanto sofrimento.

Maria passa, assim, a frequentar regularmente o grupo de dança. Poucos meses depois, recebemos o convite para nos apresentar em uma Mostra de Práticas de Saúde Mental, organizada pelo Serviço de Saúde Dr. Cândido Ferreira. Juntamos os dois grupos de dança do Ceco e começamos os ensaios de uma pequena sequência coreográfica, seguida de um momento de improviso coletivo.

Em nosso último ensaio, ao final do encontro, Maria se dá conta que não tem figurino para se apresentar. Havia faltado no ensaio anterior, no qual combinamos de experimentar e criar figurinos para apresentação. Rapidamente pego as peças que náo foram escolhidas, um tanto preocupada, pois eram pequenas e não pareciam compor entre si.

O grupo estava agitado, acertando os últimos detalhes para chegar ao evento no horário combinado. No canto da sala, Maria olha os figurinos entristecida. Pergunto se gostou de algo, e ela responde que acha que não vai dar certo, pois são pequenos, e, assim, prefere dançar em outra ocasião. Rapidamente algumas mulheres se aproximam e começam a ajudá-la com as peças, começam a vesti-la, tiram, colocam, criam, aparecem com linha e agulha e, de repente, Maria está vestida, com seu figurino árabe pronto. Peço para que se veja no espelho e novamente seu largo sorriso toma conta. Está lindamente vestida para dançar. Diz timidamente, com os olhos emocionados: "Nunca me vi tão bonita".

O corpo como questão que se impóe... É assim, vivido nesses laboratórios como "passagem" e "matéria moldável", lugar de experimentação, criação e reflexão, do qual se procura ampliar mais e mais a capacidade de afetar e ser afetado pelos encontros. Rompem-se anestesiamentos, automatismos, 
modos enrijecidos e balizados por valores morais que tendem a uma homogeneização e padronização dos sujeitos e minam o reconhecimento/produção das diferenças que carregam o germe da invenção de si e de mundos (LIBERMAN, 2008, p. 117).

São dessas produções que queremos dar língua. Produçóes que conectam os sujeitos ao plano da subjetivaçáo, ao plano da produção que é o plano do coletivo. Entendemos aqui, como nos sugere Barros e Passos (2012), coletivo náo como a soma de indivíduos ou resultado de um contrato que os indivíduos fazem entre si. Coletivo enquanto multidão, composição potencialmente ilimitada de seres tomados na proliferação das forças. Coletivo enquanto plano de produção que experimenta o tempo todo a diferenciação. Não há no coletivo propriedade particular, pessoalidades, nada que seja privado, e sim forças disponíveis a serem experimentadas.

A experiência clínica enquanto devolução do sujeito ao plano da produção em experimentação no plano coletivo, em experimentação pública, desestabilizando formas e forças instituídas, capturadas por realidades dadas e naturalizadas.

É preciso pensar a clínica enquanto abertura para produção de outras sensibilidades. Encontros como esse no Centro de Convivência carregam essa tônica, momentos quase fugazes que se eternizam na descoberta de outras conexôes possíveis. Estar sensível a formas outras de estar e se apresentar ao mundo, atentos ao próprio pulso vital, construindo singularidades resistentes aos ataques e modelos sociais, que restringem as potências e a produção de realidades criativas e pulsantes de vida (LIBERMAN, 2008).

Clínica sensível, gentil, que se apresenta à espreita, ampliando discretamente a conectividade dos encontros, expandindo e aumentando superfícies de contato ao vivido, facilitando exposiçóes às afecçôes, aos acontecimentos. Uma clínica que dança, que se movimenta, agenciando respostas outras diante dos efeitos dominantes em subjetividades capitalísticas.

\section{Conclusão}

Anunciar novas formas de lidar com as experiências é relacionar-se com elas. Há uma necessidade de entrega e confiança: entrega ao que nos conecta às zonas de comunidade e confiança ao lidar com as diferenças nas zonas de singularidades.

Afetar-se e ser afetado pelos estranhamentos vividos nos encontros, pelo que náo nos convém, pelo que também decompóe, estranha e diverge.
Habitar essas novas zonas de singularidades, nas quais se anunciam outros modos de existência. Estranhar os territórios de existência é encontrar-se com eles.

As cartografias das produçóes sensíveis no Ceco convidam ao estranhamento, ao descolar-se do senso comum, pondo-se à escuta das dissonâncias, buscando encarná-las nas práticas dos encontros, criando fissuras ao plano achatado e chapado do homogêneo, amparando as pressōes de linhas de fuga que aos poucos tomam corpo, formando outros planos, abrindo arestas, brechas, frestas, rachando, decompondo, caindo (ROLNIK, 2011).

Tentamos a-com-panhar as produçóes intensivas do Ceco nas dimensóes da micropolítica dos encontros produzidos a partir das dimensóes trabalho-clínica-gestão, entendendo esses lugares enquanto posiçôes transversalizadas que náo se separam, mas se compóem no trânsito de múltiplas linhas, emergem experiências que alargam os entendimentos de cuidado, trabalho, gestão, saúde.

O componente "anticapitalístico" dessas práticas e suas produçôes abrem múltiplas linhas de possibilidades ao enfrentamento dos processos normalizadores e disciplinarizadores, táo em alta neste momento das produçốes em saúde. Experiências possíveis para vivenciar outros modos de existência distintos dos seus, de formas não ameaçadoras (MERHY, 2009, p. 287).

Seria entáo, um possível indicador de um novo paradigma ético-estético para um devir de novas formas de vida, que implicariam náo só no fim dos atos predatórios contra as formas atuais, mas como a construção de modos de vida pautados pelas relaçóes solidárias e vivificantes dos modos de ser, nos quais as diferenças seriam expressōes da vitalidade desejante e não ameaças. Nos quais a única ética seria agir na direção de favorecer a autopoiese do viver solidário nas diferenças, individuais e coletivas. No qual a minha liberdade é a sua liberdade na diferença.

As produçóes do Ceco radicalizam as potências das tecnologias leves, seus movimentos, suas mutaçôes, suas ancoragens no território do caos ao encontro com as zonas singulares, nos palcos da diferença. Trata-se de experiências a serem compartilhadas e que se apresentam enquanto possíveis linhas de abertura ao sufocante momento de massificação em que se vive no contemporâneo. Linhas de resistência, de aberturas possíveis no curso dos processos. 


\section{Referências}

BARROS, R. B.; PASSOS, E. Clínica, política e as modulaçôes do capitalismo. Lugar Comum, São Paulo, n. 19-20, p. 159-171, 2012.

BRASIL. Portaria n ${ }^{\circ}$ 3088, de 23 de dezembro de 2011. Institui a Rede de Atenção Psicossocial para pessoas com sofrimento ou transtorno mental e com necessidades decorrentes do uso de crack, álcool e outras drogas, no âmbito do Sistema Único de Saúde (SUS). Diário Oficial [da] República Federativa do Brasil, Poder Executivo, Brasília, DF, 31 dez. 2011. Disponível em: <http://www. saude.gov.br>. Acesso em: 5 jul. 2016.

DELEUZE, G.; GUATTARI, F. Kafka: por uma literatura menor. Belo Horizonte: Autêntica, 2014.

FERIGATO, S. Cartografia dos Centros de Convivência de Campinas: Produzindo Redes de Encontros. 2013. 320 f. Tese (Doutorado em Saúde Coletiva) - Universidade Estadual de Campinas, Campinas, 2013.

GALLETTI, M. C. Oficina em Saúde Mental: instrumento terapêutico ou intercessor clínico? Goiânia: UCG, 2004.

LIBERMAN, F. Trabalho Corporal, música, teatro e dança em Terapia Ocupacional: clínica e formação. CadernosTerapia Ocupacional: Produção de Conhecimento e Responsabilidade Social, Sáo Paulo, v. 8, n. 3, p. 39-43, 2002.
LIBERMAN, F. Delicadas coreografias: instantâneos de uma terapia ocupacional. São Paulo: Summus, 2008.

LIBERMAN, F.; LIMA, E. M. F. A. O Corpo de um Cartógrafo. Interface - Comunicação, Saúde, Educação, Botucatu, v. 19, n. 52, p. 183-193, 2015.

LIMA, E. M. F. A. Por uma arte menor: ressonâncias entre arte, clínica e loucura na contemporaneidade. Interface Comunicação, Saúde, Educação, Botucatu, v. 1, n. 20, p. 317-329, 2006.

MERHY, E. E. A clínica do corpo sem órgãos, entre laços e perspicácias: em foco a disciplinarizaçáo e a sociedade de controle. Lugar Comum, São Paulo, v. 27, p. 281-306, 2009.

ROLNIK, S. Cartografia sentimental: transformaçōes contemporâneas do desejo. Porto Alegre: Editora Sulina, 2011.

SÃO PAULO. Prefeitura Municipal - PMSP. Programa de Saúde Mental. Normatização das açōes nos centros de convivência e cooperativas municipais. São Paulo, 1992.

SCHEINVAR, E. Produzir. In: FONSECA, T. M. G.; MARASCHIN, C.; NASCIMENTO, M. L. Pesquisar na diferença: um abecedário. Porto Alegre: Sulina, 2012. p. 195-197.

YASUI, S. Rupturas e encontros: desafios da Reforma Psiquiátrica brasileira. Rio de Janeiro: Fiocruz, 2010.

\section{Contribuição dos Autores}

Todos os autores contribuíram igualmente e aprovaram a versão final do texto.

\section{Fonte de Financiamento}

Este artigo não foi financiado.

\section{Notas}

${ }^{1}$ Este artigo foi elaborado a partir da pesquisa de mestrado intitulada "Centro de Convivência e Atenção Psicossocial: invenção e produção de encontros no território da diversidade”, defendida na UNESP-ASSIS em janeiro de 2016. A pesquisa foi aprovada pela Plataforma Brasil (Protocolo CAAE 44453715.4.0000.5401).

${ }^{2}$ Yasui (2010, p. 155) nos aponta um caminho para pensar a intersetorialidade: "Articular açôes integradas com os campos da Educação, Cultura, Habitação, Assistência Social, Esporte, Trabalho, Lazer, com a Universidade, o Ministério Público e as ONGs, significa construir um processo que envolve um intenso diálogo, o qual pressupóe reconhecer e respeitar as especificidades e as diversidades de cada campo; explicitar os conflitos e os interesses envolvidos, para que se possam negociar e pactuar açóes; unir potências, produzir encontros ao redor dos temas que perpassem por todos esses campos, a saber: a melhoria da qualidade de vida, a inclusão social e a construção da cidadania da população”.

${ }^{3}$ Espaço coletivo aberto de compartilhamento das experiências criado em 2005. Organizado por profissionais e gestores implicados com o projeto dos Cecos, abriga discussôes técnicas e políticas e vem trabalhando no sentido de definir parâmetros mínimos para o funcionamento dos serviços, como objetivos, constituição de equipes, estratégias, indicadores, formas de registros, banco de dados, faturamento etc. 